\title{
A One-Dimensional Hydrodynamic and Water Quality Model for a Water Transfer Project with Multihydraulic Structures
}

\author{
Yujun Yi, ${ }^{1}$ Caihong Tang, ${ }^{2}$ Zhifeng Yang, ${ }^{1}$ Shanghong Zhang, ${ }^{3}$ and Cheng Zhang ${ }^{3}$ \\ ${ }^{1}$ State Key Joint Laboratory of Environment Simulation and Pollution Control, Ministry of Education Key Laboratory of Water and \\ Sediment Science, Beijing Normal University, No. 19, XinJieKouWai St., HaiDian District, Beijing 100875, China \\ ${ }^{2}$ Ministry of Education Key Laboratory of Water and Sediment Science, School of Environment, Beijing Normal University, No. 19, \\ XinJieKouWai St., HaiDian District, Beijing 100875, China \\ ${ }^{3}$ Renewable Energy School, North China Electric Power University, No. 2, Beinong Road, Changping District, Beijing 102206, China \\ Correspondence should be addressed to Yujun Yi; yiyujun@bnu.edu.cn
}

Received 3 May 2017; Accepted 21 August 2017; Published 1 October 2017

Academic Editor: Jian G. Zhou

Copyright (C) 2017 Yujun Yi et al. This is an open access article distributed under the Creative Commons Attribution License, which permits unrestricted use, distribution, and reproduction in any medium, provided the original work is properly cited.

\begin{abstract}
The long Middle Route of the South to North Water Transfer Project is composed of complex hydraulic structures (aqueduct, tunnel, control gate, diversion, culvert, and diverted siphon), which generate complex flow patterns. It is vital to simulate the flow patterns through hydraulic structures, but it is a challenging work to protect water quality and maintain continuous water transfer. A one-dimensional hydrodynamic and water quality model was built to understand the flow and pollutant movement in this project. Preissmann four-point partial-node implicit scheme was used to solve the governing equations in this study. Water flow and pollutant movement were appropriately simulated and the results indicated that this water quality model was comparable to MIKE 11 and had a good performance and accuracy. Simulation accuracy and model uncertainty were analyzed. Based on the validated water quality model, six pollution scenarios $\left(Q_{1}=10 \mathrm{~m}^{3} / \mathrm{s}, Q_{2}=30 \mathrm{~m}^{3} / \mathrm{s}\right.$, and $Q_{3}=60 \mathrm{~m}^{3} / \mathrm{s}$ for volatile phenol (VOP) and contaminant mercury ( $\mathrm{Hg})$ ) were simulated for the MRP. Emergent pollution accidents were forecasted and changes of water quality were analyzed according to the simulations results, which helped to guarantee continuously transferring water for a large water transfer project.
\end{abstract}

\section{Introduction}

Water resource is an important natural source for supporting and maintaining human health and social sustainable development [1]. Population growth, urban expansion, industrialization, consumption pattern, and energy structure changes result in the increased demand for freshwater resources [2]. According to the China Water Resources Bulletin 2014, the national average rainfall was $622.3 \mathrm{~mm}$, while the average rainfall was $316.9 \mathrm{~mm}$ in the Haihe basin and $1100.63 \mathrm{~mm}$ in the Yangtze River basin. The corresponding surface water resources were $26,263.9 \times 10^{8} \mathrm{~m}^{3}, 98 \times 10^{8} \mathrm{~m}^{3}$ and $10,020.3$ $\times 10^{8} \mathrm{~m}^{3}$, respectively. This extremely uneven distribution of water resources pushed China to build the Middle Route of the South to North Water Transfer Project (MRP) to alleviate the shortage of water resources in the north and fully utilize the water resources in the Yangtze River basin.
The MRP consists of open channel and six types of hydraulic structures. Complex structures are the typical characteristics of this project. The transferred water needs to meet the requirement of the Class II water quality standards of the Environmental Quality Standards for Surface Water of China (GB3838-2000). Open channel is the main way to transfer water in south of the Beijing territory for this project. Meanwhile, transferred water in the open channel has a high risk of water pollution resulting from atmosphere deposition, groundwater pollution, discharged polluted water, and sudden pollution accidents [3]. Therefore, protecting water quality is still an emphasis on water transfer and water resources management [4].

To ensure water quality of the transferred water to meet the Class II standards of water quality, it is vital to make clear the movement rules of flow and pollutant. Especially for the MRP, water flow is disturbed by lots of complex 
hydraulic structures in the channel. Figuring out the flow patterns and transfer process of pollutants are difficult to be observed at structures. Thus, water quality simulation can be utilized in water quality protection and water resources management [5]. From the original Streeter-Phelps equation to now integrated water quality models, from zerodimensional model to multidimensional model, water quality models have achieved great progress. The typical representatives include WASP [6], QUAL2E [7], Environmental Fluid Dynamics Code (EFDC) [8], Computational Fluid Dynamics (CFD) [9], and DHI MIKE (Danish Hydraulic Institute) [10]. These models were widely applied to rivers, lakes, estuaries, and water transfer projects with large amount of hydraulic structures (gates, culverts, dams, and bridges) [1013]. Although water flow was difficult to be determined when it gets through hydraulic structures, hydraulic regulation was crucial for water resources management and water quality control [14]. In simulating complex water flow, DHI MIKE 11 is a widely used tool of simulating complex flows [10]. It was employed to simulate the water flow and pollutant movement in an open channel of the Middle Route of the South to North Water Transfer Project (MRP) with complex hydraulic structures [13]. The hydrodynamic module (HD) of MIKE 11 was coupled with MIKE FLOOD, MIKE SHE, and reservoir scheduling module to expose the influence of hydraulic structures on hydrological regime and benefit water resources management and flood forecasting $[10,12,15]$.

Although the above-mentioned dominating water quality models have been constantly improving, for the complicated MRP, there is no existing model that could directly be used for this project. Another model WHYSWESS (watershed hydrology, hydraulic, sediment transport, water quality, and ecology simulation system) integrates distributed hydrological model, water quality module, and habitat simulation modules of benthos, fish, and vegetation [16, 17]. Additionally, it is capable of simulating flows through complex hydraulic structures. A one-dimensional water quality module was built on WHYSWESS platform, which simulated the pollutant movement in the complex MRP.

This paper focuses on a one-dimensional water quality model (WHYSWESS-WQ) for the long distance water transfer project (MRP) with complex hydraulic structures. This model included a hydrodynamic module (WHYSWESSHD) and an advection-dispersion module (WHYSWESS$\mathrm{AD})$. Flows in open channel and six types of hydraulic structures were simulated based on this model. Simulation results based on the WHYSWESS indicated that it was a good water quality model when compared with that relying on MIKE 11. The validated model was then applied to simulate and predicate sudden pollution accidents for the MRP. Six scenarios were presented to provide suggestions for water resources management and forecasting of emergent pollution accidents in large water transfer projects.

\section{Study Area}

The MRP stretches across the North China Plain and has a length of approximately $1277 \mathrm{~km}$. The whole MRP is a combination of open channel and 1750 hydraulic structures
[13]. It is a magnificent project in China and results in a total submerged land area of $30,800 \mathrm{hm}^{2}$ [19]. This project transfers water from Danjiangkou Reservoir to Tuancheng Lake and is constructed mainly to supply drinking water for cities in North China, including the capital city Beijing. Since December 12, 2014, the MRP has transferred water 5,000 million $\mathrm{m}^{3}$ and more than 40 million people have used it (http://www.nsbd.gov.cn/zx/mtgz/201608/t20160829_ 446841.html). Besides, the MRP has a strict requirement for water quality on the basis of Environmental Quality Standards for Surface Water of China (GB3838-2002). Its long distance, complex hydraulic structures, and strict water quality requirement push researchers to study the processes of hydrodynamics and water quality from planning to construction and finally operation $[13,20]$.

This study was conducted for the approximate $42 \mathrm{~km}$ canal from the starting point Xishi to the ending point Beijuma River nearby Beijing (Figure 1). Averaged bottom width ranges from $7.5 \mathrm{~m}$ to $11 \mathrm{~m}$ in this reach. The slope and longitudinal gradient are approximately 2.5 and 1/25000, respectively. The largest discharge should be less than $70 \mathrm{~m}^{3} / \mathrm{s}$. Six types of hydraulic structures (inverted siphons, culverts, gates, diversions, tunnels, and aqueduct) were considered in this reach. All these hydraulic structures are vital to successfully transferring and diverting water from south to north, but it is tough to accurately simulate the flow field around the structure (Figure 1 and Table 1).

\section{Method}

\subsection{Governing Equations}

3.1.1. Hydrodynamic Module. The Saint-Venant equations, classical unsteady open channel flow governing equations, describe the flow of one-dimensional rivers or channels based on the following three hypotheses: (1) distribution of velocity along cross section is uniform and water pressure is regarded as the hydrostatic pressure; (2) as a result of the small river slope, $\sin \alpha \approx \tan \alpha$; (3) water flow is described by the gradually varied flow [21]. Saint-Venant equations are still employed to indicate water flow in this WHYSWESS-HD and are represented as follows [13]:

Continuity equation is

$$
B \frac{\partial h}{\partial t}+\frac{\partial Q}{\partial x}=q .
$$

Momentum equation is

$$
\begin{aligned}
\frac{\partial Q}{\partial t}+ & 2 \frac{Q}{A} \frac{\partial Q}{\partial x}+\left(g A-B \frac{Q^{2}}{A^{2}}\right) \frac{\partial h}{\partial x}-\left.\left(\frac{Q}{A}\right)^{2} \frac{\partial A}{\partial x}\right|_{h} \\
& +\frac{g Q|Q|}{C^{2} A R}=0,
\end{aligned}
$$

where $x$ and $t$ denote the spatial and temporal coordinates, respectively; $Q$ and $h$ denote the crosssectional discharge and water level, respectively; $A$ 
TABLE 1: List of hydraulic structures of study canal.

\begin{tabular}{lccc}
\hline Structure (Abbreviation) & Symbol & Name & Distance from initial section (km) \\
\hline Aqueduct (Aq) & Aq1 & Shuibeigou aqueduct & 32.133 \\
Culvert (C) & C1 & Leizixi culvert & 20.374 \\
& C2 & Leizidong culvert & 20.944 \\
Diversion (D) & D1 & Jingkeshan diversion & 3.697 \\
& D2 & Xiacheting diversion & 27.994 \\
Check gate (G) & G1 & Beiyishui check gate & 4.87 \\
& G2 & Fenzhuang River check gate & 19.575 \\
& INS1 & Beiyishui inverted siphon & 4.39 \\
Inverted siphon (INS) & INS2 & Qilizhuanggou inverted siphon & 10.437 \\
& INS3 & Matougou inverted siphon & 17.077 \\
& INS4 & Fenzhuang River inverted siphon & 19.352 \\
Tunnel (T) & INS5 & Nanjuma River inverted siphon & 38.348 \\
& INS6 & Beijuma River inverted siphon & 41.25 \\
& T1 & Xishi tunnel & 0.045 \\
\end{tabular}

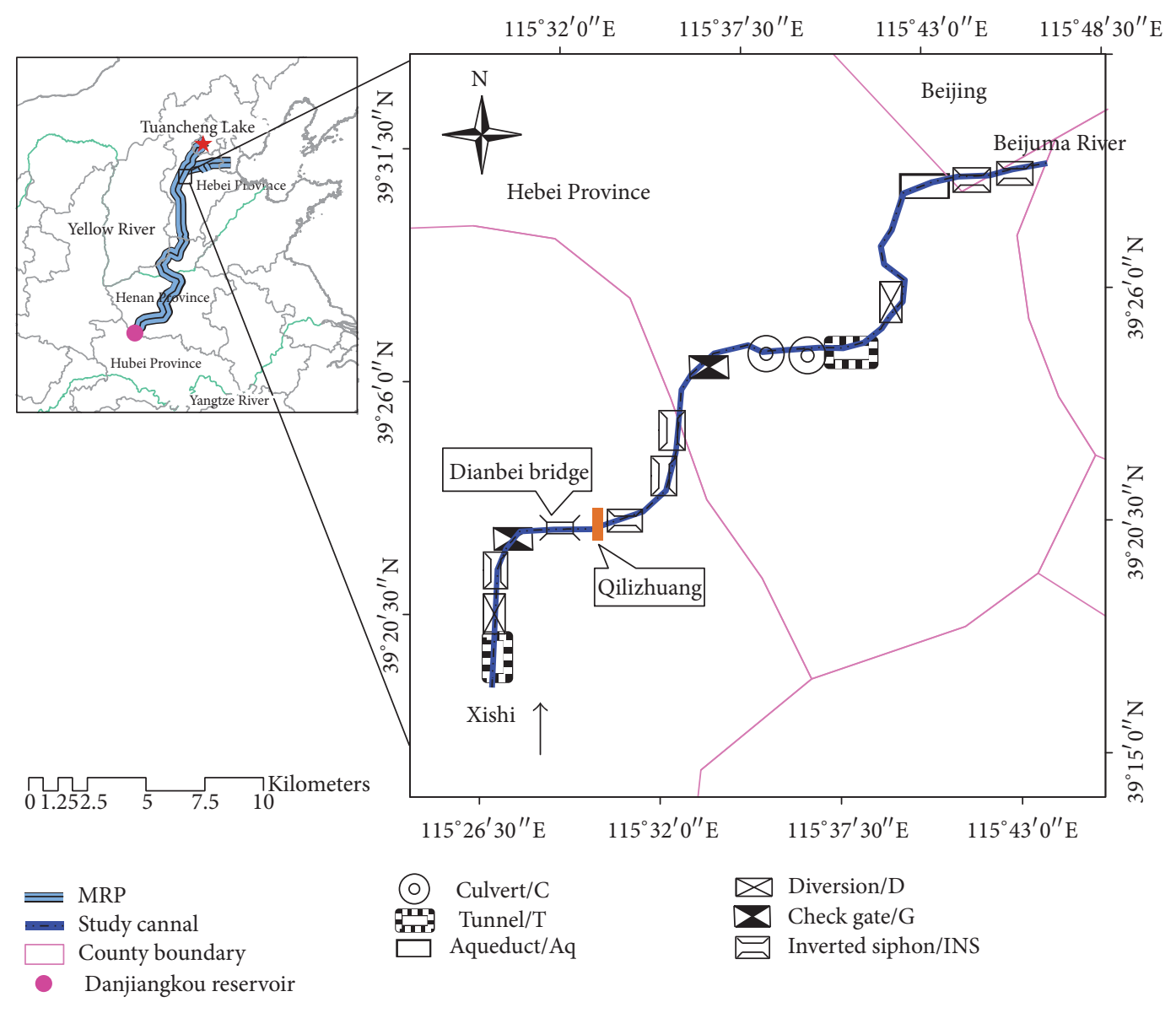

Figure 1: Map of study canal.

and $R$ denote the cross-sectional area and hydraulic radius, respectively; $B$ denotes the width of the river; $q$ denotes the lateral inflow; $C$ denotes the Chezy coefficient; and $g$ denotes the gravitational acceleration.

3.1.2. Water Quality Module. One-dimensional river advection-dispersion equation was used to analyze the movement patterns of pollutant in this WHYWESS-AD. The specific equation of mass conservation was used to describe the oneorder degradation process of pollutant in open channel and represented as follows [22]:

$$
\frac{\partial C_{1} A}{\partial t}+\frac{\partial C Q}{\partial x}=\frac{\partial}{\partial x}\left[E \frac{\partial C_{1} A}{\partial x}\right]-A K_{d} C_{1}+C_{2} q
$$


TABLE 2: Solution methods of hydraulic structures in two water quality models.

\begin{tabular}{|c|c|c|}
\hline Items & WHYSWESS-WQ & MIKE 11 \\
\hline Aqueduct & Open channel flow with branches & Open channel flow \\
\hline Tunnel & Open channel flow with branches & Open channel flow \\
\hline Control gate & $\begin{array}{l}\text { Discrete gate flow formula is coupled with discrete } \\
\text { Saint-Venant equations. Initial water level, discharge, } \\
\text { and process of control gate opening are provided to } \\
\text { automatically select corresponding flow calculation } \\
\text { formula }\end{array}$ & $\begin{array}{l}\text { Discharge point, single setting; three controlling modes } \\
(H / Q, d H / d Q \text {, sum } Q) \text {; appropriate discrete solution is } \\
\text { coupled }\end{array}$ \\
\hline Diversion & Lateral outflow, source-sink term in continuity equation & Lateral outflow, inner boundary \\
\hline Culvert & $\begin{array}{l}\text { According to the water level, flow contains open flow; } \\
\text { half-pressure flow and pressure flow }\end{array}$ & $\begin{array}{l}\text { Culvert module includes zero flow, upstream controlled } \\
\text { flow, downstream controlled flow for different } \\
\text { computational purposes. Above flow modes consists of } \\
\text { many flow situations and equation. Discrete equations } \\
\text { are solved with Saint-Venant equations }\end{array}$ \\
\hline Inverted siphon & $\begin{array}{l}\text { Discrete pressure flow equation is coupled with discrete } \\
\text { Saint-Venant equations to solve together }\end{array}$ & As a culvert with fully submerged flow \\
\hline
\end{tabular}

where $C_{1}$ is the concentration of pollutant; $E$ is the river longitudinal dispersion coefficient; $K_{d}$ is the first-order decay coefficient; and $C_{2}$ is the concentration of pollutant from point-source pollution.

3.2. Solution of Equations. The Saint-Venant equations are first-order quasilinear hyperbolic partial differential equations and are difficult to directly get the analytical solutions. Therefore, numerical methods, such as finite difference method, finite element method, finite volume method, and characteristic line method, are common ways to solve them [23].

The Preissmann four-point partial-node implicit scheme is a representative implicit difference scheme and has fast convergence, high efficiency, and good stability [24]. It was used in WHYSWESS-HD. Water level $h$ and discharge $Q$ were treated as dependent variables. The form of Preissmann fourpoint partial-node implicit scheme was shown in Figure 2. The discrete Saint-Venant equations are presented as follows:

$$
\begin{aligned}
& a_{1 i} h_{i}^{j+1}-c_{1 i} Q_{i}^{j+1}+a_{1 i} h_{i+1}^{j+1}+c_{1 i} Q_{i+1}^{j+1}=e_{1 i} \\
& a_{2 i} h_{i}^{j+1}+c_{2 i} Q_{i}^{j+1}-a_{2 i} h_{i+1}^{j+1}+d_{2 i} Q_{i+1}^{j+1}=e_{2 i}
\end{aligned}
$$

where $a_{1 i}=1, c_{1 i}=2 \theta\left(\Delta t / \Delta s_{i}\right)\left(1 / B_{i+1 / 2}^{j+\theta}\right), e_{1 i}=h_{i}^{j}+h_{i+1}^{j}-$ $((1-\theta) / \theta) c_{1 i}\left(Q_{i+1}^{j}-Q_{i}^{j}\right)+2 \Delta t q_{i+1 / 2}^{j+\theta} / B_{i+1 / 2}^{j+\theta}, a_{2 i}=2 \theta(\Delta t /$ $\left.\Delta s_{i}\right)\left[\left(Q_{i+1 / 2}^{j+\theta} / A_{i+1 / 2}^{j+\theta}\right)^{2} B_{i+1 / 2}^{j+\theta}-g A_{i+1 / 2}^{j+\theta}\right], c_{2 i}=1-4 \theta(\Delta t /$ $\left.\Delta s_{i}\right)\left(Q_{i+1 / 2}^{j+\theta} / A_{i+1 / 2}^{j+\theta}\right), d_{2 i}=1+4 \theta\left(\Delta t / \Delta s_{i}\right)(Q / A)_{i+1 / 2}^{j+\theta}, \quad e_{2 i}=$ $((1-\theta) / \theta) a_{2 i}\left(h_{i+1}^{j}-h_{i}^{j}\right)+\left[1-4(1-\theta)\left(\Delta t / \Delta s_{i}\right)(Q / A)_{i+1 / 2}^{j+\theta}\right] Q_{i+1}^{j}+$ $\left[1+4(1-\theta)\left(\Delta t / \Delta s_{i}\right)(Q / A)_{i+1 / 2}^{j+\theta}\right] Q_{i}^{j}+2 \Delta t\left(Q_{i+1 / 2}^{j+\theta} / A_{i+1 / 2}^{j+\theta}\right)^{2} \times$ $\left(A_{i+1}\left(h_{i+1 / 2}^{j+\theta}\right)-A_{i}\left(h_{i+1 / 2}^{j+\theta}\right)\right) / \Delta s_{i}-2 \Delta t\left(g n^{2} Q_{i+1 / 2}^{j+\theta}\left|Q_{i+1 / 2}^{j+\theta}\right| B_{i+1 / 2}^{j+\theta} \mid\right.$ $\left.\left(A_{i+1 / 2}^{j+\theta}\right)^{2}\left(A_{i+1 / 2}^{j+\theta} / B_{i+1 / 2}^{j+\theta}\right)^{1 / 3}\right)+2 \Delta t Q_{i+1 / 2}^{j+\theta} q_{i+1 / 2}^{j+\theta} / A_{i+1 / 2}^{j+\theta}, \varphi_{i+1 / 2}^{j+1}=$ $\theta\left(\left(\varphi_{i}^{j+1}+\varphi_{i+1}^{j+1}\right) / 2\right)+(1-\theta)\left(\left(\varphi_{i}^{j+1}+\varphi_{i+1}^{j}\right) / 2\right) \cdot \varphi$ refers to the coefficient of $A, B, Q, h$, and so on. $A_{i+1}\left(h_{i+1 / 2}^{j+\theta}\right)$ and $A_{i}\left(h_{i+1 / 2}^{j+\theta}\right)$ represent the sectional areas $A_{i+1}$ and $A_{i}$ at the water level of $h_{i+1 / 2}^{j+\theta}$, respectively; $i$ is the cross section number.

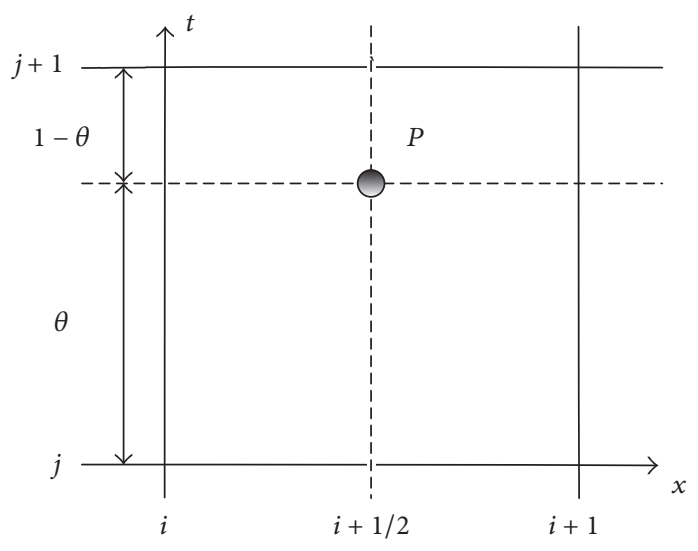

FIGURE 2: Sketch of the Preissmann four-point implicit scheme of WHYSWESS-HD.

3.3. Hydraulic Structures. The main canal of the MRP is made up of open channel and complex hydraulic structures. Movement of flows and pollutants around structures were accurately simulated using WHYSWESS-WQ model. The specific description of hydraulic structures was listed in Table 2. Flows in aqueduct and tunnel were rectangular free surface flow in the MRP, so aqueduct and tunnel were set as open channels in WHYSWESS-WQ. Flows in gate were calculated according to the gate outflow formula. Water flows in diversion were regarded as the lateral outflow through adding source-sink term in continuity equation. Flows in culvert were calculated based on the water flow patterns. Flows in inverted siphon were regarded as the pressure flow. Discrete pressure flow equation was coupled with discrete Saint-Venant equations to be solved (Table 2).

\section{Results and Discussion}

\subsection{Calibration and Validation}

4.1.1. Hydrodynamic Model. The MRP is a long artificial canal, which has a uniform roughness coefficient and regular 


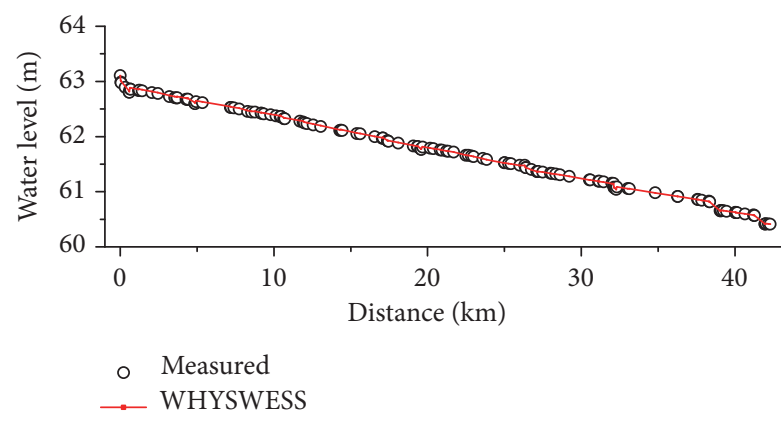

(a)

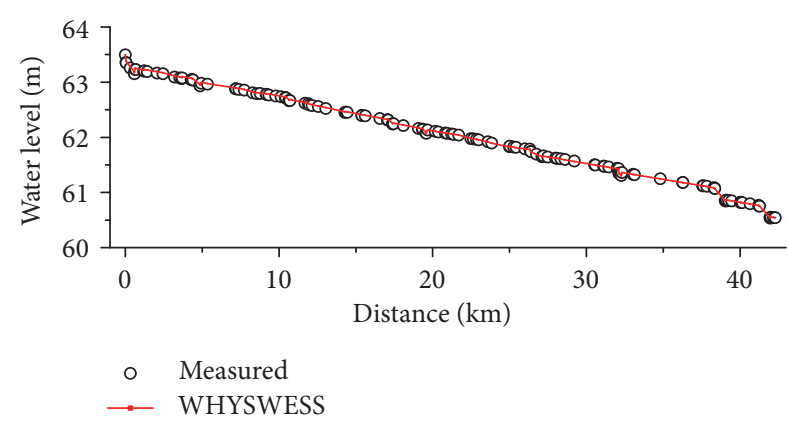

(b)

FIGURE 3: Calibration and validation results of WHYSWESS-HD ((a) is the calibration results at $Q=60 \mathrm{~m}^{3} / \mathrm{s}$ and (b) is the validation results at $Q=70 \mathrm{~m}^{3} / \mathrm{s}$ ).

TABLE 3: Comparison of parameters between WHYSWESS-WQ and MIKE 11.

\begin{tabular}{|c|c|c|}
\hline Parameters & WHYSWESS-WQ & MIKE 11 \\
\hline \multicolumn{3}{|l|}{ Hydrodynamic module } \\
\hline \multicolumn{3}{|l|}{ Validation } \\
\hline Absolute error (m) & $-0.009 \sim 0.022$ & $-0.147 \sim 0.356$ \\
\hline Relative error (\%) & $-0.015 \sim 0.034$ & $-0.24 \sim 0.56$ \\
\hline \multicolumn{3}{|l|}{ Water quality module } \\
\hline Dispersion coefficient $\left(\mathrm{m}^{2} / \mathrm{s}\right)$ & 3.47 & 4 \\
\hline \multicolumn{3}{|l|}{ Decay coefficient $(/ \mathrm{h})$} \\
\hline $\mathrm{TP}$ & 0.26 & 0.24 \\
\hline $\mathrm{COD}_{\mathrm{Mn}}$ & 0.097 & 0.084 \\
\hline $\mathrm{NH}_{3}-\mathrm{N}$ & 0.21 & 0.24 \\
\hline $\mathrm{F}$ & 0.083 & 0.072 \\
\hline \multicolumn{3}{|l|}{ Water quality prediction } \\
\hline Dispersion coefficient $\left(\mathrm{m}^{2} / \mathrm{s}\right)$ & 3.47 & 4 \\
\hline \multicolumn{3}{|l|}{ Decay coefficient $(/ \mathrm{h})$} \\
\hline \multicolumn{3}{|l|}{ Toxic organic } \\
\hline $\mathrm{Hg}$ & \multicolumn{2}{|l|}{0} \\
\hline \multicolumn{3}{|l|}{ Indissoluble heavy metal } \\
\hline VOP & \multicolumn{2}{|c|}{$0.00417^{\mathrm{a}}$} \\
\hline
\end{tabular}

Note. ${ }^{a}$ Based on Zhang [18].

shape. Therefore, steady flow was chose to test the models. Water levels at discharge of $Q=60 \mathrm{~m}^{3} / \mathrm{s}$ were employed to calibrate and that of $Q=70 \mathrm{~m}^{3} / \mathrm{s}$ at Qilizhuang section were used to validate the WHYSWESS-HD. Discharges and water levels were, respectively, set as the upstream and downstream boundaries in this hydrodynamic module. Calibrated and validated results were shown in Figure 3.

According to the calibration and validation results of WHYSWESS-HD, the error range was relatively low (Figure 3). Maximum absolute error of water levels was $0.022 \mathrm{~m}$ and the maximum relative error was $0.034 \%$ (Table 3 ). A knee point appeared at this section (Xiacheting tunnel) away from the initial section of $28 \mathrm{~km}$ (Table 1). The big disturbance might be resulted from the flow around tunnel.

A one-dimensional water quality model based on MIKE 11 was built for the study canal in Tang et al. [13]. Method, calibration, and validation of this model were specifically described there.

4.1.2. Water Quality Model. Based on the WHYSWESSHD, WHYSWESS-AD for Total Phosphorus (TP), Potassium Permanganate Index $\left(\mathrm{COD}_{\mathrm{Mn}}\right)$, Fluoride $(\mathrm{F})$, and Ammonia Nitrogen $\left(\mathrm{NH}_{3}-\mathrm{N}\right)$ were established. Concentrations of these four pollutants from October 13, 2008, to August 9, 2009, were simulated and simulation results were used to validate the WHYSWESS-WQ. Validation results indicated that the water quality model adequately reflected change trend of concentrations of these four pollutants.

Only the first-order decay processes of $\mathrm{TP}, \mathrm{COD}_{\mathrm{Mn}}$, $\mathrm{NH}_{3}-\mathrm{N}$, and $\mathrm{F}$ have been considered in this paper. Water quality simulation results based on MIKE 11 were closer to the measured data than simulation results based on WHYSWESS, which had a larger dispersion coefficient (Figure 4 and Table 3). When comparing the calibration and validation results referenced from Tang et al. [13] with that of WHYSWESS-WQ, WHYSWESS-WQ had a smaller longitudinal dispersion coefficient and decay coefficient of $\mathrm{NH}_{3}-\mathrm{N}$ and had a larger decay coefficient of TP, $\mathrm{COD}_{\mathrm{Mn}}$, and F (Table 3).

4.2. Parameter Settings. Longitudinal dispersion coefficient was a crucial parameter in water pollution accidents, and it was easily affected by hydrodynamic and geometrical parameters [25]. According to model calibration and validation results, WHYSESS-WQ had a smaller longitudinal dispersion coefficient than MIKE 11, which showed that a larger water flow velocity gradient indicated a larger pollutant transport capacity. Same constant boundaries and initial conditions were adopted in two water quality models. The dispersion coefficient of WHYSWESS-WQ was less than that of MIKE 11. This result showed that a discrete degree of water body simulated by WHYSWESS-WQ was more intense than that by MIKE 11. The first-order degradation coefficients of TP and $\mathrm{COD}_{\mathrm{Mn}}$ in WHYSWESS were slightly larger than those in MIKE 11 and were smaller than those of $\mathrm{NH}_{3}-\mathrm{N}$ and $\mathrm{F}$. Different equation solutions of the Saint-Venant equations and flow patterns through structures lead to the different degradation coefficients. Therefore, the two water quality 

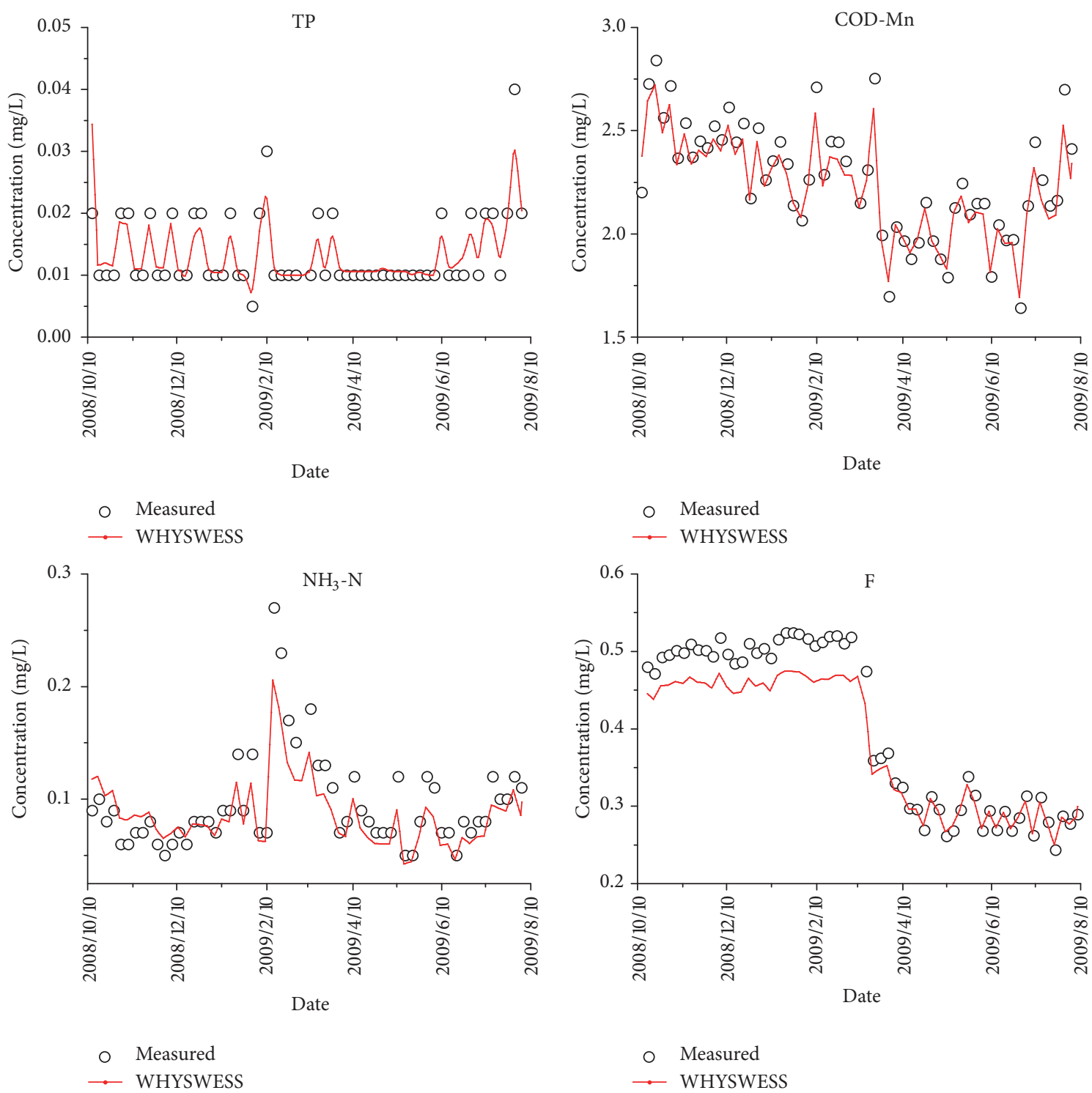

FIGURE 4: Validation results of water quality model based on the WHYSWESS (the point is the measured data; the red line is the simulated results).

models presented here are reasonable and WHSWESS is an effective tool of simulating the long canal with complex hydraulic structures. The first-order decay was considered in WHYSWESS for $\mathrm{COD}_{\mathrm{Mn}}$ and F. Respirations of algae and benthos, oxidation of $\mathrm{NH}_{3}-\mathrm{N}$, and transformation between resolvable $\mathrm{P}$ and released $\mathrm{P}$ from sediment were considered in WHYSWESS. Yet sediment in channel is neglected in this paper. Only the first-order decay for all materials was considered in MIKE 11.

4.3. Simulation Accuracy. From Table 3 and Figure 3, WHYSWESS-HD had higher calculation accuracy than MIKE 11. Maximum absolute error and maximum relative error of water levels were, respectively, $0.022 \mathrm{~m}$ and $0.034 \%$ in WHYSWESS-HD. Validation results in MIKE 11 also showed the same trend and had an averaged water depth of $4.3 \mathrm{~m}$. From validation results of hydrodynamic module in MIKE 11, the maximum absolute error was $0.356 \mathrm{~m}$, and the maximum relative error was $0.56 \%$. These error ranges represented an acceptable simulation error (Table 3 ).

The MRP had characteristics of regular trapezoidal section, uniform longitudinal slope, and gradually decreased discharges from south to north. The study canal was divided into 143 sections in this paper. Calculation results indicated that WHYSWESS had higher simulation accuracy than MIKE 11. Two main aspects lead the different accuracy between models: setting of hydraulic structures and the solution formats of governing equations.

Hydraulic structures were considered differently in governing equations between WHSWESS-WQ and MIKE 11. Except aqueducts and tunnels, other structures such as control gate, diversion, culvert, and inverted siphon were treated differently in WHYSWESS-WQ and MIKE 11 (Table 2). Although hydrodynamic module of MIKE 11 could directly 
set hydraulic structures (weir, bridge, culvert, and pump), there was a lack of modules for diversion, inverted siphon, and aqueduct. Therefore, diversions, inverted siphons, and aqueducts were appropriately adjusted in MIKE 11 to achieve better simulation results. Aqueducts and tunnels were solved as open channel just the same as the WHYSWESS-WQ. Flow through inverted siphons was pressure flow and was generalized into culverts in MIKE 11 (Table 2).

For the solution formats of Saint-Venant equations, WHYSWESS-HD is based on the Preissmann four-point partial-node implicit scheme, while MIKE 11 is based on the six-point Abbott-Ionescu implicit scheme. Other than the Preissmann four-point partial-node implicit scheme, main idea of the latter was using staggered computational grid of alternating $Q$ (discharge) and $h$ (water level). In momentum equation, $Q$ was the center point, and forward difference scheme was used to deal with time $t$. Water level $h$ was conducted as the central point. Central difference for space was used to achieve the discrete $x$ in continuity equation (Danish Hydraulic Institute). MIKE 11 has higher simulation accuracy than HEC-RAS for a $43 \mathrm{~km}$ long river [26]. The same rule was derived in by Bennett et al. [27]. Four-point operators Preissmann implicit finite difference scheme was used in HEC-RAS $[28,29]$. In the case of the same river roughness, boundaries, and initial conditions, different simulation results originated from the solution of equations. According to the comparison of HEC-RAS and MIKE 11, six-point Abbott-Ionescu implicit scheme was more accurate than Preissmann implicit finite difference scheme in calculating the river water flow. From this perspective, more accurate results of WHYSWESS-WQ than MIKE 11 benefited from the calculation of hydraulic structures, which reversely explained and supported that solution formats of governing equations were the main reason for different calculation results in the two models.

4.4. Model Uncertainty. Model uncertainty in river water quality modeling mainly results from parameter estimations, input data and model structure [30]. River cross section and river bed roughness coefficient used in this study were the theory data and did not consider the virtual conditions for the artificial canal. This difference can lead to model uncertainty, and also, the initial water level and boundary conditions result in model uncertainty [31]. The measured water levels, discharges, and concentrations of pollutant can result in model uncertainty, because of monitoring methodology and subjective judgment of staff [32]. Additionally, model structure is another main reason for inconsistent coefficients and calculation accuracy. As commercial software, MIKE 11 had a more mature model framework and a wider application in hydrodynamic simulation and water quality prediction than WHYSWESS which later appeared. In summary, the calculation precision and simulation efficiency of model established by the WHYSWESS-WQ were acceptable. As an open-source water quality model, WHYSWESS-WQ would provide more references and suggestions for further studies and be more meaning.

4.5. Water Quality Prediction. Sudden pollution accidents were simulated to provide early warning and emergency response for water quality conservation and eutrophication control $[6,33]$. One single or one type of pollutant is not enough to forecast pollution accidents and give advice for water resources management and regulation [18]. Water quality of Danjiangkou Reservoir (the water source region of the MRP) has to meet the requirement of the Environmental Quality Standards for Surface Water of China. Due to clean water sources and artificial channels of the MRP, alga and sediments in canals were neglected. The MRP stretches across the Hebei Province from south to north, and 697 bridges have been built to recover transportation along the canal [13]. These bridges had potential pollution risk for transferred water [3].

Volatile phenol (VOP), as a high toxic organic compound, was widely used in the cooking wastewater at present, and its solution had a serious effect on human health [34]. Except organics, heavy metals are also the main pollutants that are capable of being accumulated in human bodies and other aquatic organisms and even resulting in deadly hazard [35]. Heavy metal pollution has been attracting more attentions [36]. Road transport of raw materials made an increased emergent pollution risks for the MRP under influences of weather, road, and environmental factors [3]. To forecast water quality changes and provide suggestions for water resources regulation, typical nonconservative contaminant VOP and conservation contaminant mercury $(\mathrm{Hg})$ were chosen as the emergent pollutants for the MRP in this study. Point-source pollution occurred in the MRP which was simulated using the WHYSWESS-WQ. The Dianbei bridge is located at the place away from the starting section $9.17 \mathrm{~km}$ in the study canal (Figure 1). As a national second-class bridge, it is busy to be an important traffic artery in the Hebei Province, China. Therefore, Dianbei bridge is selected as the accidental place of emergent pollution.

In order to compare the accuracy of the WHYSWESSWQ, sudden pollution accidents were also simulated by MIKE 11. Point-source pollution was directly added to the initial conditions in WHYSWESS, while it was treated as the inner boundary in MIKE 11. Based on WHYSWESSWQ and MIKE 11, six scenarios (two pollutants (volatile phenol (VOP) and contaminant mercury $(\mathrm{Hg})$ ) under three upstream discharges $\left(Q_{1}=10 \mathrm{~m}^{3} / \mathrm{s}, Q_{2}=30 \mathrm{~m}^{3} / \mathrm{s}\right.$, and $Q_{3}=$ $\left.60 \mathrm{~m}^{3} / \mathrm{s}\right)$ ) were simulated in this research (Figures 5 and 6). Leakage concentration $C_{1}$ was supposed to be $100 \mathrm{mg} / \mathrm{L}$ and the emission speed $\left(q^{\prime}\right)$ was $1 \mathrm{~m}^{3} / \mathrm{s}$. Longitudinal dispersion coefficients were achieved from the calibration results of water quality modules and decay coefficients were derived from previous research (Table 3 )

Simulated concentrations of $\mathrm{Hg}$ at three discharges had the same change trend in WHYSWESS-WQ and MIKE 11. Larger discharges lead to quicker diffusion and dispersion of $\mathrm{Hg}$ and VOP. When pollutants arrived at the end section, the arrival time decreased gradually (Figures 5 and 6). Although $\mathrm{Hg}$ and VOP had the same leakage concentration, $\mathrm{Hg}$ could be only diffused and VOP could be diffused and dispersed. The maximum concentration of $\mathrm{Hg}$ was the same as VOPs, which was also reasonable. The pollution area was mainly controlled by the pollutant load. When incoming discharge was close to $Q_{1}$, enough time was needed to remove $\mathrm{Hg}$ 

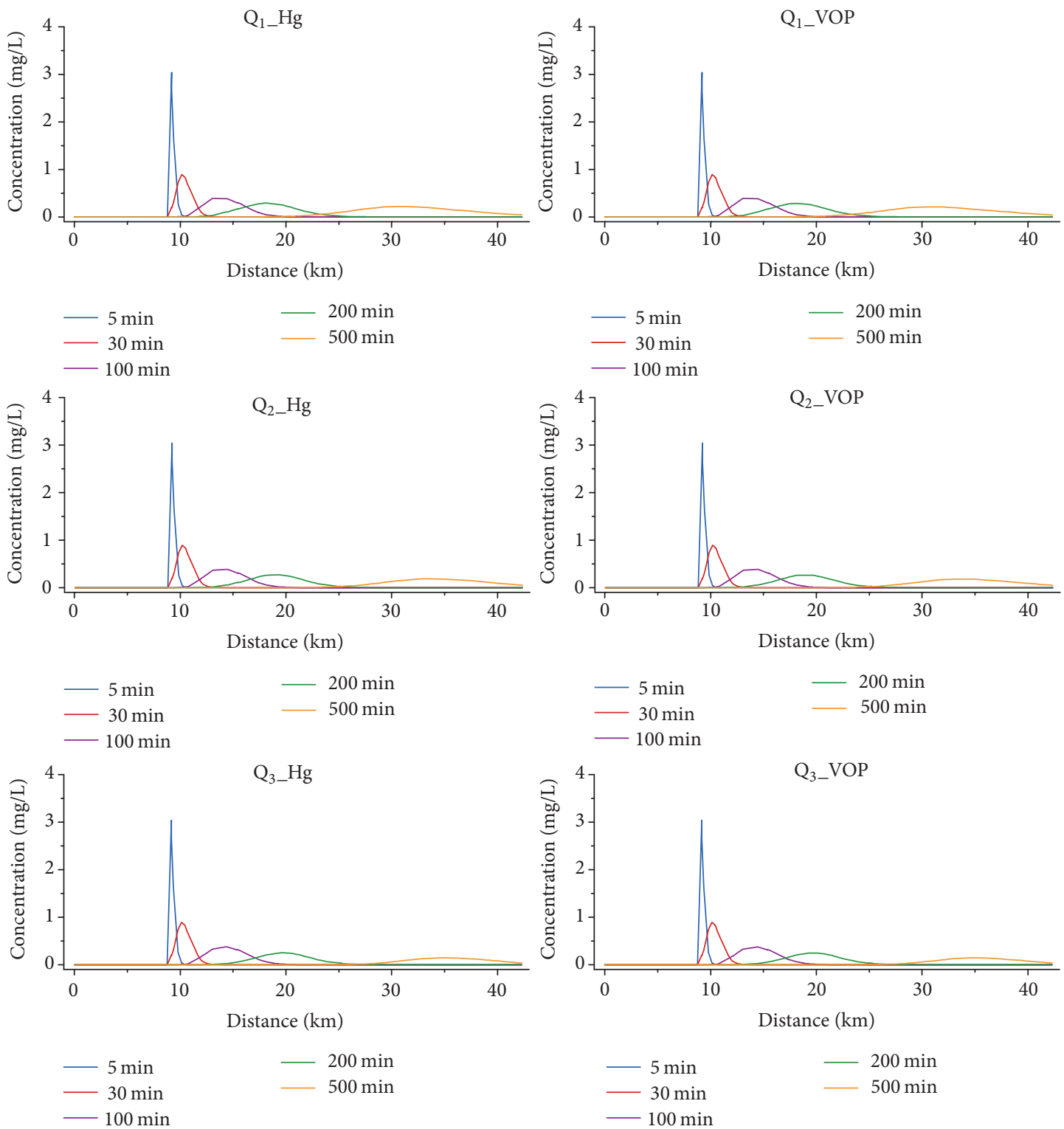

FIGURE 5: Water quality simulation based on WHYSWESS at Dianbei bridge $\left(Q_{1}=10 \mathrm{~m}^{3} / \mathrm{s}, Q_{2}=30 \mathrm{~m}^{3} / \mathrm{s}\right.$, and $\left.Q_{3}=60 \mathrm{~m}^{3} / \mathrm{s}\right)$.

and VOP in the reach. Pollutants were dissolved and carried in water, which resulted in the coincidence of simulation results of hydrodynamic and water quality module. Therefore, pollutant concentrations based on WHYSWESS had a more change than that based on MIKE 11 due to the larger hydrodynamic simulation errors of MIKE 11 . The water standard Class II (GB3838-2000) indicated that concentrations of $\mathrm{Hg}$ and VOP should not exceed $0.005 \mathrm{mg} / \mathrm{L}$ and $0.002 \mathrm{mg} / \mathrm{L}$, respectively, for transferred water. Simulation results showed when the peak concentration arrived at the end of the study reach, all concentrations of organic pollutants and heavy metals exceeded the standard values even at the lowest discharge of $Q_{1}$. Under this serious pollution, it is indispensable to strengthen the monitoring and management of water quality for the MRP. Large transfer projects (for an example of the MRP) cost amount of manpower and public finance; relative policy and laws should be established and perfected to protect water resources safety and make full use of the transferred water.

\section{Conclusions}

A one-dimensional hydrodynamic and water quality model (WHYSWESS-WQ) was built for simulating the flow field and pollutants movement through the MRP, a long distance water transfer project with multiple types of hydraulic structures. The Preissmann four-point partial-node implicit scheme was chosen to solve the governing equations in this study. Validation results of water quality represented that this model could well describe transport regularities of flow and pollutants with a maximum relative error of $0.034 \%$, and it was capable of simulating and providing reference 

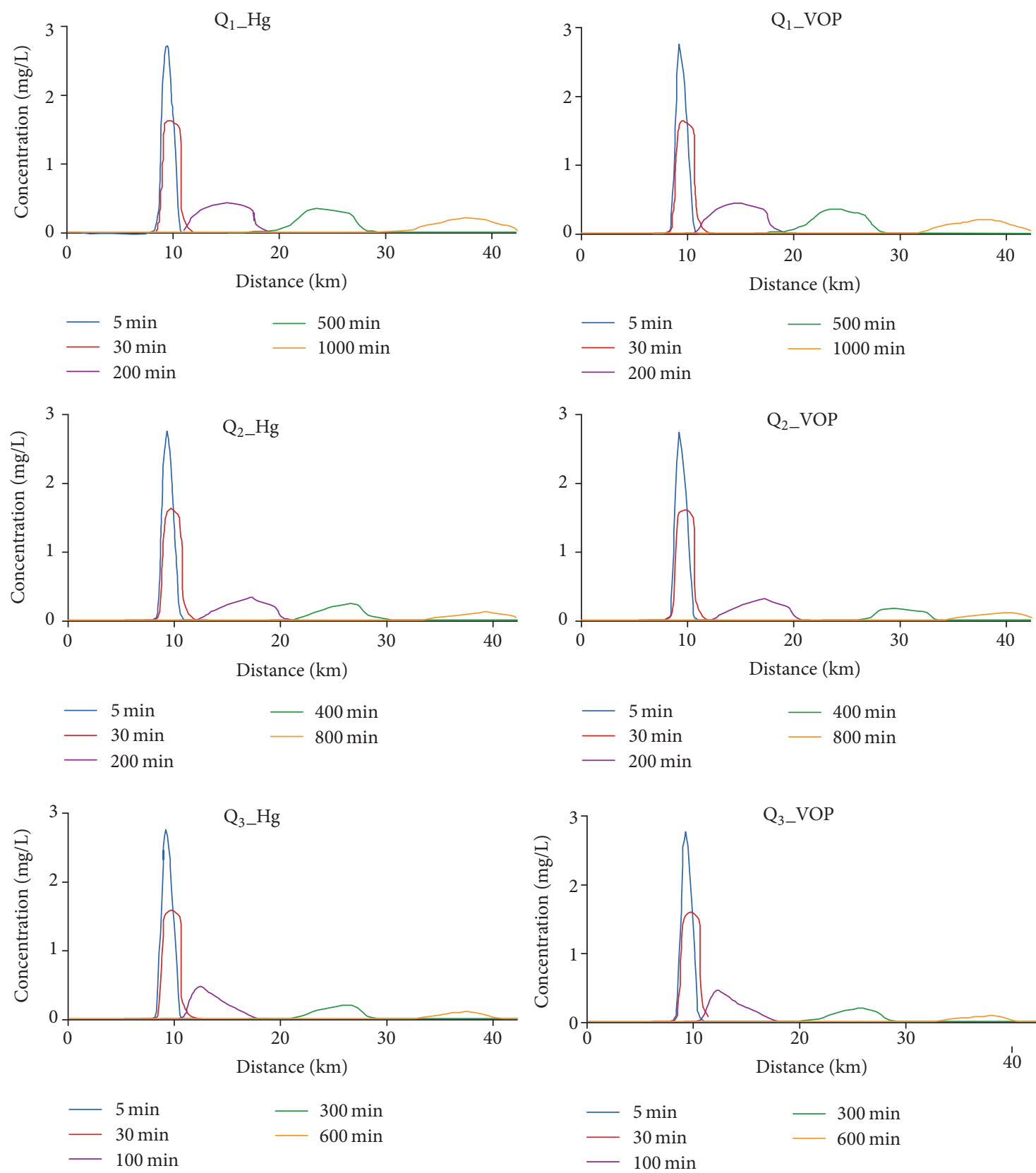

FIGURE 6: Water quality simulation based on MIKE 11 at Dianbei bridge $\left(Q_{1}=10 \mathrm{~m}^{3} / \mathrm{s}, Q_{2}=30 \mathrm{~m}^{3} / \mathrm{s}\right.$, and $\left.Q_{3}=60 \mathrm{~m}^{3} / \mathrm{s}\right)$.

for pollution simulations in large water transfer projects with complex hydraulic structures. Simulation results were compared with those simulated by MIKE 11. Comparison showed WHYSWESS-WQ had higher simulation accuracy than MIKE 11 when water flow was calculated in a long water transfer project with complex hydraulic structures. Six water quality predication scenarios (discharge of $Q_{1}=10 \mathrm{~m}^{3} / \mathrm{s}, Q_{2}$ $=30 \mathrm{~m}^{3} / \mathrm{s}$, and $Q_{3}=60 \mathrm{~m}^{3} / \mathrm{s}$ ) results showed that concentrations of VOP and $\mathrm{Hg}$ at the last section of the study's reach exceeded Class II standard when the discharge was more than $Q_{1}=10 \mathrm{~m}^{3} / \mathrm{s}$. This suggestion would be helpful for the water quality protection and water resources management, and relative policy and laws should be established to protect the water quality.

\section{Notations}
A: Cross-sectional area
$B$ : Width of river
C: Chezy coefficient
$C_{1}$ : Concentration of pollutants
$\mathrm{C}_{2}$ : Concentration of point source
$E$ : Longitudinal dispersion coefficient
g: Gravitational acceleration
$h$ : Cross-sectional water level 
$i$ : Number of cross sections

$j: \quad$ Space step

$K_{d}$ : First-order decay coefficient

n: Time step

Q: Cross-sectional discharge

q: Lateral inflow

$q^{\prime}$ : Pollution emission speed

$R:$ Hydraulic radius

$t$ : Temporal coordinate

$x$ : Spatial coordinate

$\varphi:$ Coefficient

$\theta$ : Time weighting factor.

\section{Conflicts of Interest}

The authors declare that they have no conflicts of interest.

\section{Acknowledgments}

This study was supported by the National Natural Science Foundation of China (no. 51439001 and no. 51279220) and National Key R\&D Program (Grant no. 2016YFC0502209).

\section{References}

[1] Y. Sun, Z. Chen, G. Wu et al., "Characteristics of water quality of municipal wastewater treatment plants in China: Implications for resources utilization and management," Journal of Cleaner Production, vol. 131, pp. 1-9, 2016.

[2] R. Bagatin, J. J. Klemeš, A. P. Reverberi, and D. Huisingh, "Conservation and improvements in water resource management: A global challenge," Journal of Cleaner Production, vol. 77, pp. 1-9, 2014.

[3] C. Tang, Y. Yi, Z. Yang, and J. Sun, "Risk analysis of emergent water pollution accidents based on a Bayesian Network," Journal of Environmental Management, vol. 165, pp. 199-205, 2016.

[4] N. C. Kunz, C. J. Moran, and T. Kastelle, "Implementing an integrated approach to water management by matching problem complexity with management responses: A case study of a mine site water committee," Journal of Cleaner Production, vol. 52, pp. 362-373, 2013.

[5] K. W. Chau, "Integrated water quality management in Tolo Harbour, Hong Kong: a case study," Journal of Cleaner Production, vol. 15, no. 16, pp. 1568-1572, 2007.

[6] S. Liang, H. Jia, C. Yang, C. Melching, and Y. Yuan, "A pollutant load hierarchical allocation method integrated in an environmental capacity management system for Zhushan Bay, Taihu Lake," Science of the Total Environment, vol. 533, pp. 223237, 2015.

[7] V. Palmieri and R. J. de Carvalho, "Qual2e model for the Corumbataí River," Ecological Modelling, vol. 198, no. 1-2, pp. 269-275, 2006.

[8] G. Wu and Z. Xu, "Prediction of algal blooming using EFDC model: Case study in the Daoxiang Lake," Ecological Modelling, vol. 222, no. 6, pp. 1245-1252, 2011.

[9] V. T. Nguyen, C. S. Moreno, and S. Lyu, "Numerical simulation of sediment transport and bedmorphology around Gangjeong Weir on Nakdong River," KSCE Journal of Civil Engineering, vol. 19, no. 7, pp. 2291-2297, 2014.
[10] J. R. Thompson, H. R. Sørenson, H. Gavin, and A. Refsgaard, "Application of the coupled MIKE SHE/MIKE 11 modelling system to a lowland wet grassland in southeast England," Journal of Hydrology, vol. 293, no. 1-4, pp. 151-179, 2004.

[11] F. Cheng, U. Zika, K. Banachowski, D. Gillenwater, and T. Granata, "Modelling the effects of dam removal on migratory walleye (Sander vitreus) early life-history stages," River Research and Applications, vol. 22, no. 8, pp. 837-851, 2006.

[12] S. Förster, C. Chatterjee, and A. Bronstert, "Hydrodynamic simulation of the operational management of a proposed flood emergency storage area at the Middle Elbe River," River Research and Applications, vol. 24, no. 7, pp. 900-913, 2008.

[13] C. Tang, Y. Yi, Z. Yang, and X. Cheng, "Water pollution risk simulation and prediction in the main canal of the South-toNorth Water Transfer Project," Journal of Hydrology, vol. 519, pp. 2111-2120, 2014.

[14] O. Fovet, G. Belaud, X. Litrico et al., "A model for fixed algae management in open channels using flushing flows," River Research and Applications, vol. 28, no. 7, pp. 960-972, 2012.

[15] L. Wen, R. Macdonald, T. Morrison, T. Hameed, N. Saintilan, and J. Ling, "From hydrodynamic to hydrological modelling: Investigating long-term hydrological regimes of key wetlands in the Macquarie Marshes, a semi-arid lowland floodplain in Australia," Journal of Hydrology, vol. 500, pp. 45-61, 2013.

[16] Y. Yi, C. Tang, Z. Yang, and X. Chen, "Influence of Manwan Reservoir on fish habitat in the middle reach of the Lancang River," Ecological Engineering, vol. 69, pp. 106-117, 2014.

[17] S. Zhang, Z. Xia, and T. Wang, "A real-time interactive simulation framework for watershed decision making using numerical models and virtual environment," Journal of Hydrology, vol. 493, pp. 95-104, 2013.

[18] H. J. Zhang, Study on prediction model of Volatile Phenol pollution accidents in natural river of Dalian city, Dalian University of Technology, China, 2009.

[19] H. J. Zhai, L. Chen, and J. Zhang, "Study on environmental protection of the resettlement and reconstruction around danjiangkou reservoir in the first-stage middle route of the south-to-north water diversion project," South-to-North Water Diversion and Water Science \& Technology, vol. 10, pp. 477-485, 2011.

[20] S. Li, J. Li, and Q. Zhang, "Water quality assessment in the rivers along the water conveyance system of the Middle Route of the South to North Water Transfer Project (China) using multivariate statistical techniques and receptor modeling," Journal of Hazardous Materials, vol. 195, pp. 306-317, 2011.

[21] F. Saleh, A. Ducharne, N. Flipo, L. Oudin, and E. Ledoux, "Impact of river bed morphology on discharge and water levels simulated by a 1D Saint-Venant hydraulic model at regional scale," Journal of Hydrology, vol. 476, pp. 169-177, 2013.

[22] K. El Kadi Abderrezzak, R. Ata, and F. Zaoui, “One-dimensional numerical modelling of solute transport in streams: The role of longitudinal dispersion coefficient," Journal of Hydrology, vol. 527, pp. 978-989, 2015.

[23] S. N. Kuiry, W. Wu, and Y. Ding, "A hybrid finite-volume/finitedifference scheme for one-dimensional boussinesq equations to simulate wave attenuation due to vegetation," in Proceedings of the World Environmental and Water Resources Congress 2011: Bearing Knowledge for Sustainability, pp. 2114-2124, usa, May 2011.

[24] D. A. Lyn and P. Goodwin, "Stability of a general preissmann scheme," Journal of Hydraulic Engineering, vol. 113, no. 1, pp. 1628, 1987. 
[25] Y. H. Zeng and W. X. Huai, "Estimation of longitudinal dispersion coefficient in rivers," Journal of Hydro-Environment Research, vol. 8, no. 1, pp. 2-8, 2014.

[26] S. W. Jiang and W. U. Yong-Xin, "A comparison and analysis of flood control capacity of the nandu river based on MIKE 11 and HEC-RAS model," China Rural Water \& Hydropower, vol. 2, pp. 46-49, 2014.

[27] T. H. Bennett, R. Walton, P. D. Dickerson, and J. W. Howard, "Comparison of HEC-RAS and MIKE11 unsteady flow modeling for the Tillamook Valley," In Critical Transitions in Water and Environmental Resources Management, vol. 128, pp. 1-8, 2004.

[28] B. N. Bockelmann, E. K. Fenrich, B. Lin, and R. A. Falconer, "Development of an ecohydraulics model for stream and river restoration," Ecological Engineering, vol. 22, no. 4-5, pp. 227-235, 2004.

[29] USACE, 2010. HEC-RAS, River Analysis System. US Army Corps of Engineers. Hydrologic Engineering Center, v4.1, CPD68.

[30] K.-E. Lindenschmidt, K. Fleischbein, and M. Baborowski, "Structural uncertainty in a river water quality modelling system," Ecological Modelling, vol. 204, no. 3-4, pp. 289-300, 2007.

[31] Y. P. Li, C. Y. Tang, Z. B. Yu, and K. Acharya, "Uncertainty and sensitivity analysis of large shallow lake hydrodynamic models," Advances in Water Science, vol. 2, pp. 271-227, 2012.

[32] A. F. Blumberg and N. Georgas, "Quantifying uncertainty in estuarine and coastal ocean circulation modeling," Journal of Hydraulic Engineering, vol. 134, no. 4, pp. 403-415, 2008.

[33] Y. Rui, D. Shen, S. Khalid, Z. Yang, and J. Wang, "GISbased emergency response system for sudden water pollution accidents," Physics and Chemistry of the Earth, vol. 79-82, pp. 115-121, 2015.

[34] T. Chen, X. Huang, M. Pan, S. Jin, S. Peng, and P. H. Fallgren, "Treatment of coking wastewater by using manganese and magnesium ores," Journal of Hazardous Materials, vol. 168, no. 2-3, pp. 843-847, 2009.

[35] Y. Yi, Z. Yang, and S. Zhang, "Ecological risk assessment of heavy metals in sediment and human health risk assessment of heavy metals in fishes in the middle and lower reaches of the Yangtze River basin," Environmental Pollution, vol. 159, no. 10, pp. 2575-2585, 2011.

[36] X. Wei, B. Gao, P. Wang, H. Zhou, and J. Lu, "Pollution characteristics and health risk assessment of heavy metals in street dusts from different functional areas in Beijing, China," Ecotoxicology and Environmental Safety, vol. 112, pp. 186-192, 2015. 


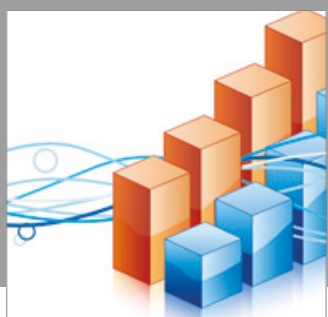

Advances in

Operations Research

vatersals

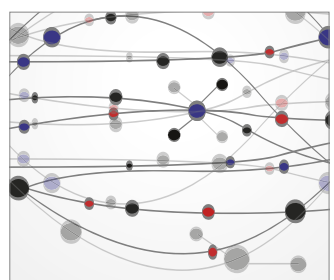

\section{The Scientific} World Journal
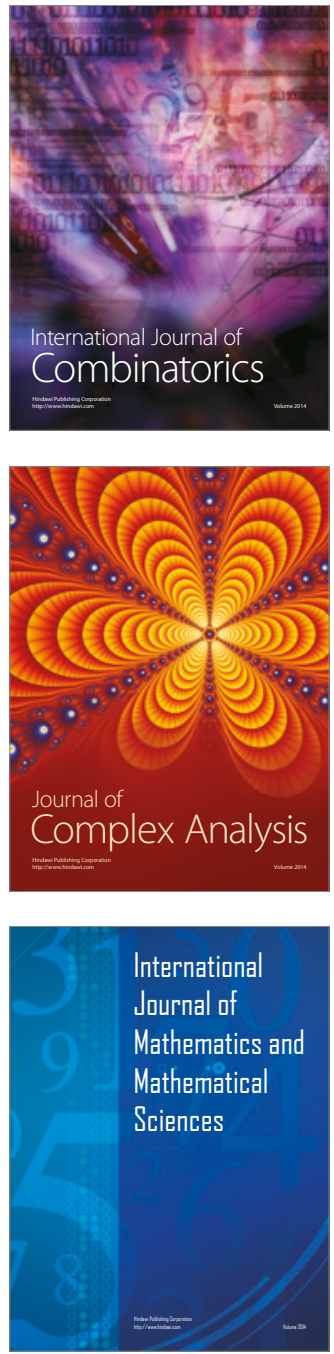
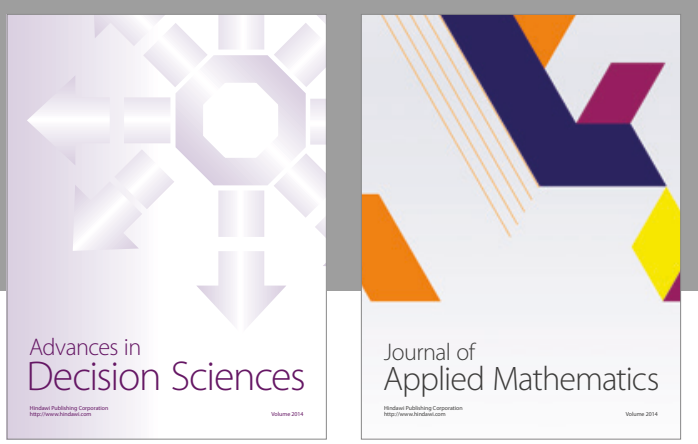

Algebra

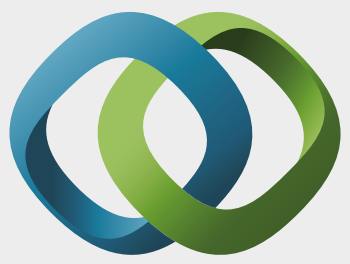

\section{Hindawi}

Submit your manuscripts at

https://www.hindawi.com
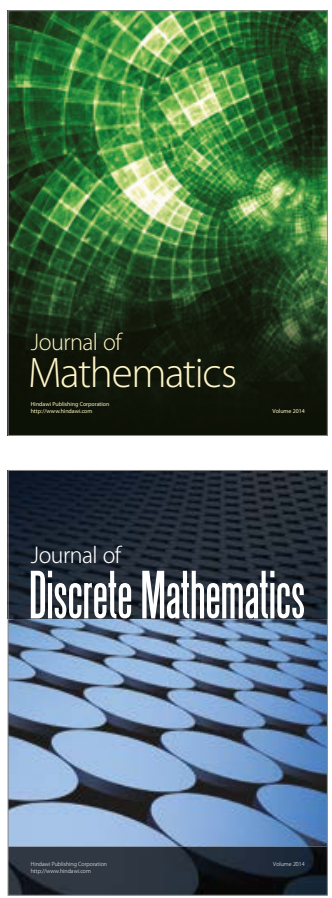

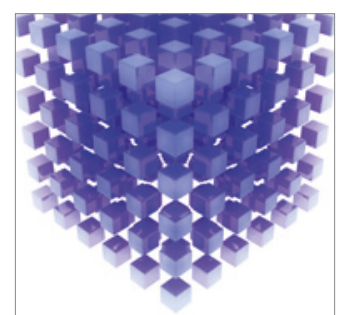

Mathematical Problems in Engineering
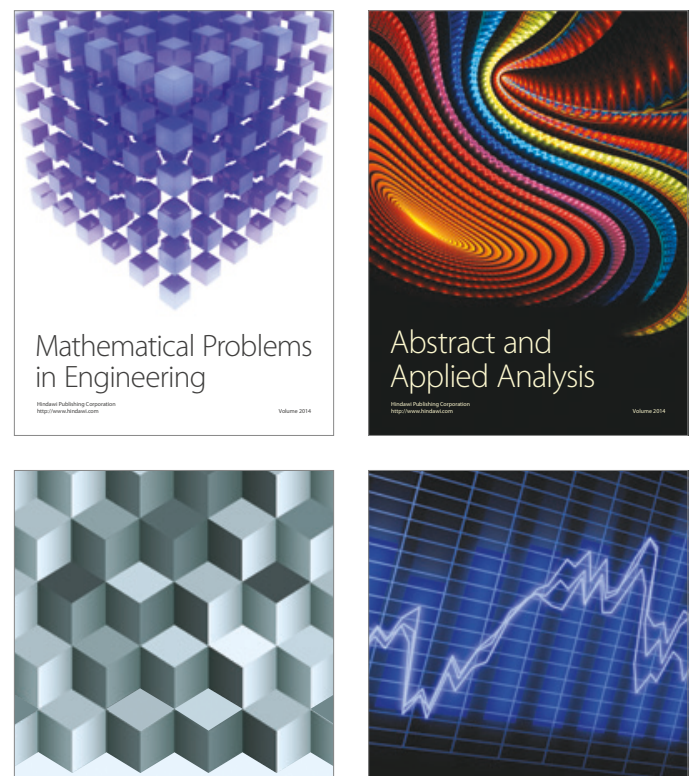

Journal of

Function Spaces

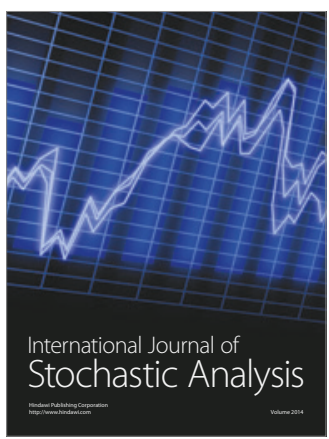

Probability and Statistics
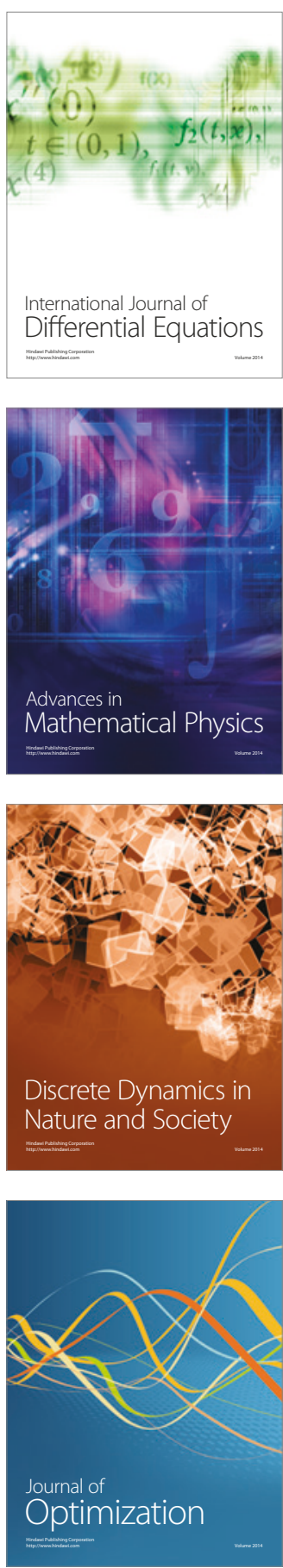